in favour of the immunity conferred by inoculation was sufficiently strong to make it desirable that it should continue to be used. Professor Wright, of course, was in favour of this being done, but he described the precautions which should be taken, as recently detailed in The Hospital (September 28th). Surgeon-General Henry Cayley thought that the eridence proved the value of inoculation for a certain time, possibly from five to six months, and he believed that ino ulation made the attacks less severe. Dr. Howard Tooth said that although his figures were small they were favourabls to inoculation. He thought that the more severely the person reacted to the inoculation, the less likely was he to be immune. In Bloemfontein officers who had had severe reaction did not seem to be protected; in which he would seem to be in accord with Professor Wright. Dr. H. D. Rolleston believed there were s sveral different strains of the typhoid bacillus, and that an individual infected with one strain was not proof against lother strains, a doctrine which evidently cuts at the root of the specificity of enteric fever.

\section{INTUSSUSCEPTION IN INFANTS.}

$\mathrm{A}_{\mathrm{T}}$ the last meeting of the Clinical Society an interesting question arose as to the method of operating for intussusception in infants. Mr. Wallis showed the case- one of acute intussusception in a child aged seven months, successfully treated by operation. The operation was performed 33 hours after the first onset of the symptoms. The abdomen was opened by an incision in the upper part of the right semilunar line, and the intussusception, which occupied the situation of the hepatic flexure of the colon, was drawn out of the incision. By gentle traction and pressure it was gradually reduced. The intussuscepted portion was seven inches long. The operation lasted 20 minutes. The bowels acted the next day, and the child recovered. In discussing this case Mr. Barker asked for more particulars of the operation, for he considered that it was of great importance in such cases that only a small opening into the abdomen should be made, and that the gut, instead of being brought outside, should be manipulated with the first finger in the abdomen and the thumb on the abdominal wall. Mr. Wallis, in reply, stated that in this case it had been impossible to reduce the intussusception within the abdomen, and that it had therefore been brought outside, when it was easily reduced. There can, of course, be no doubt that Mr. Barker is right-if his contention is that those cases do the best in which it is possible to obtain reduction by the manipulation which he described. But, equally of course, when such means fail further measures must be undertaken.

\section{REVERSED TEST TYPES.}

A WRITER in the British Optical Journal revives the suggestion that in examining the eye for refraction the test types should be placed behind the patient who should look at them by means of a mirror placed in front of him at half the distance which usually intervenes between the eye and the object. It is a well-known device, but one which is not made use of as often as it might be. Many surgeries and consulting rooms do not permit of the full six metres between the patient and the card, and under such circumstances various allowances have to be made which are apt to detract somewhat from the accuracy of the results; but by placing a good mirror at about three metres from the patient, and making him look at the reflection of the types instead of at the types themselves, the difficulty of the distance is at once got over. There are also several other advantages in this method, among them being the fact that the examiner stands by or behind the patient, and thus is able to change and point to the various tests without crossing the room, while one source of light is sufficient for all purposes. Many a surgeon whose consulting room is only a small one will find that by using a mirror in this way he will save himself much trouble in doing refractions. Reversed letters must be used, and the greatest care must be taken to keep the mirror thoroughly clean, for on this all depends.

\section{ANEURYSM OF THE AORTA.}

Dr. Whiphaм, ${ }^{1}$ medical registrar St. George's Hospital, records a remarkable case of aneurysm of 16 years' duration, which ended by rupture externally. In 1884 the patient began to suffer from incessant cough and thoracic pains, and in 1886 a swelling was noticed on the right side of the sternum. He was then admitted to St. George's, when there was a rounded, regular, smooth tumour, $3 \frac{1}{2}$ inches in diameter, occupying the first and second right interspaces and the adjacent edge of the sternum. It was expansile, but no bruit was heard over it, though one was present in the right subclavian and carotid arteries. The voice was hoarse, the cough was suggestive of pressure, and there was inspiratory stridor. During his first three weeks in hospital the aneurysm increased rapidly in size till it eroded the whole of the upper part of the sternum, measuring $6 \frac{1}{4}$ by $4 \frac{1}{2}$ inches. Two eminences appeared on the surface and the skin over the tumour was tense, shiny, and discoloured. The patient was described at this time as being "weak, ill, and hopeless," and it is an interesting thing to note that, notwithstanding his apparently desperate condition, he began gradually to mend, the tumour steadily decreased in size and seemed to consolidate, while the prominences disappeared. After lying in bed for eight months the patient got up again, the pulsating area then measuring only $1 \frac{1}{2}$ by $1 \frac{1}{4}$ inch, and he was discharged in January, 1887. The treatment adopted had consisted of scruple to $\frac{1}{2}$-drachm doses of potassium iodide, with morphine for the relief of pain, while the fluid part of his diet was restricted to a pint in the 24 hours. A year after his discharge he returned to work, which, however, did not involve manual labour. In 1892, after a violent cold with cough, he had violent shooting pains in the neck and left arm, and a rapid bulging of the aneurysm at the episternal notch. He was again admitted suffering from such dyspnœa and dysphagia that his condition was regarded as very serious. Again the iodide treatment was resumed, with the result that he much improved, and was discharged. In 1895 he was admitted with pleurisy and pneumonia. From this time the aneurysm became markedly worse, but he continued to work on and off until the beginning of 1899 . There was still no bruit over the aneurysm, and no pressure symptoms beyond slight stridor and a brassy 